\title{
Influence of Phosphating and Silicate Post-Sealing on Corrosion Behavior of Rebar Steel as Construction Material in Sodium Chloride Solution
}

\author{
Xiaojiang Yang \\ Capital University of Physical Education and Sports, Beijing 100091, China \\ E-mail: teacher yang100@,126.com
}

Received: 28 October 2021 / Accepted: 30 November 2021 / Published: 5 January 2022

\begin{abstract}
Construction rebar steel is mainly used as the skeleton of concrete members. Improving its corrosion resistance is of great significance to ensure the stability of concrete members. In this study, zinc based phosphating and silicate sealing were combined to improve the corrosion resistance of construction rebar steel. The morphology, surface composition and corrosion resistance of rebar steel after phosphating and silicate sealing were studied. The results show that the appearance of rebar steel after phosphating and silicate sealing is black and gray. The surface components mainly include $\mathrm{Zn}, \mathrm{P}, \mathrm{O}, \mathrm{Na}$ and $\mathrm{Si}$ elements. The proper concentration of sodium silicate in the sealing solution can repair the crystallization defects and improve the compactness and corrosion resistance of the phosphating film. When the concentration of sodium silicate in the sealing solution is $10 \mathrm{~g} / \mathrm{L}$, the corrosion current density of the phosphating film decreases obviously and the charge transfer resistance increases about three times. The phosphating combined with silicate sealing treatment is beneficial to prevent the penetration of corrosive medium and increase the corrosion resistance, so as to provide better corrosion protection for construction rebar steel.
\end{abstract}

Keywords: Construction rebar steel; Phosphating; Sealing; Sodium silicate; Corrosion resistance;

\section{FULL TEXT}

(C) 2022 The Authors. Published by ESG (www.electrochemsci.org). This article is an open access article distributed under the terms and conditions of the Creative Commons Attribution license (http://creativecommons.org/licenses/by/4.0/). 